\title{
Analysis of the Development Process of Payment Methods and Mobile Payment Technology Diffusion Trend in China
}

\author{
Yingying Li, Ying $\mathbf{L i}^{*}$ \\ School of Business, East China University of Science and Technology, Shanghai, China \\ Email: pingguowuai@126.com, *liying@ecust.edu.cn
}

How to cite this paper: Li, Y. Y., \& Li, Y. (2020). Analysis of the Development Process of Payment Methods and Mobile Payment Technology Diffusion Trend in China. Technology and Investment, 11, 1-11. https://doi.org/10.4236/ti.2020.111001

Received: January 10, 2020

Accepted: February 25, 2020

Published: February 28, 2020

Copyright ( 2020 by author(s) and Scientific Research Publishing Inc. This work is licensed under the Creative Commons Attribution International License (CC BY 4.0).

http://creativecommons.org/licenses/by/4.0/

\section{(c) (i) Open Access}

\begin{abstract}
Under the background of current development of China's payment system, this paper researched the diffusion trend of mobile payment products and constructed a payment product diffusion model based on the Bass model that considers repeated purchases. Through a comparative study between traditional products, such as debit and credit cards, and mobile payment products, such as mobile banking; as well as a comparative study between mobile payment products issued by large state-owned banks and joint-stock banks; the paper discussed mobile payment promotion strategies among different types of payment institutions. Moreover, the fitting effect between the model in this paper and the traditional Bass model is verified by empirical analysis.
\end{abstract}

\section{Keywords}

Mobile Payment, Payment System, Technology Diffusion

\section{Introduction}

In the 70 years since the founding of New China, with the development of economy and viability, the people's payment methods have changed many times. The payment market has undergone multiple stages of development with different payment methods dominating-from card payment, which generated in the era of material scarcity period, to the payment system in which cash payments, bank card payments, Internet payments, and mobile payments coexist. With the popularization of mobile Internet and smart devices, mobile payment has received more and more attention from the academia and the financial industry in the global payment field. According to different payment methods, mobile payment can be divided into remote payment and near field payment. 
Mobile remote payment refers to a payment method that uses the Internet, telecommunications network, etc. to exchange information with the back-end server without using a physical recipient terminal. Mobile near field payment refers to a payment in which the physical acceptance terminal accesses the acquiring network online or offline to complete transaction. The development of mobile payment has shown a strong growth trend. Especially in China, according to data released by the Payment and Settlement Department of the People's Bank of China, the transaction scale of China’s mobile payment market in 2013 was still $¥ 9.64$ trillion (PBC, 2013), while it reached $¥ 347.11$ trillion in 2019, that is an increase of 35 times. Even in 2019, it increased by $25.13 \%$ year-on-year, maintaining a rapid growth trend (PBC, 2019). The scale of the mobile payment market is shown in Figure 1. Meanwhile, according to data from research firm Forrester, in 2017 China's mobile payment market size has reached 90 times that of the US mobile payment market, and has become the world's largest mobile payment market (Sohu, 2018). Mobile payment has become one of the main payment methods for consumers.

Mobile payment has been generally accepted by consumers, but the mobile payment products released by major mobile payment participants, such as commercial banks, communication operators, and third-party payment institutions, have different social acceptance levels. And there are even significant differences among different types of commercial banks. The two state-owned Banks, industrial and commercial bank of China and China construction bank, have more than 200 million mobile banking users. Among the joint-stock Banks, China merchants bank has about 50 million mobile banking users. At present, most of researches on mobile payment are discussion on the influencing factors of consumers' willingness to adopt mobile payments based on models such as TAM, UTAUT, TTF (Merhi, Hone, \& Tarhini, 2019; Kalinic, Marinkovic, Molinillo et al., 2019; Zhou, 2012; Zhou, 2013). While few studies involve questions such as "Can mobile payments still maintain a good growth trend?" and "How

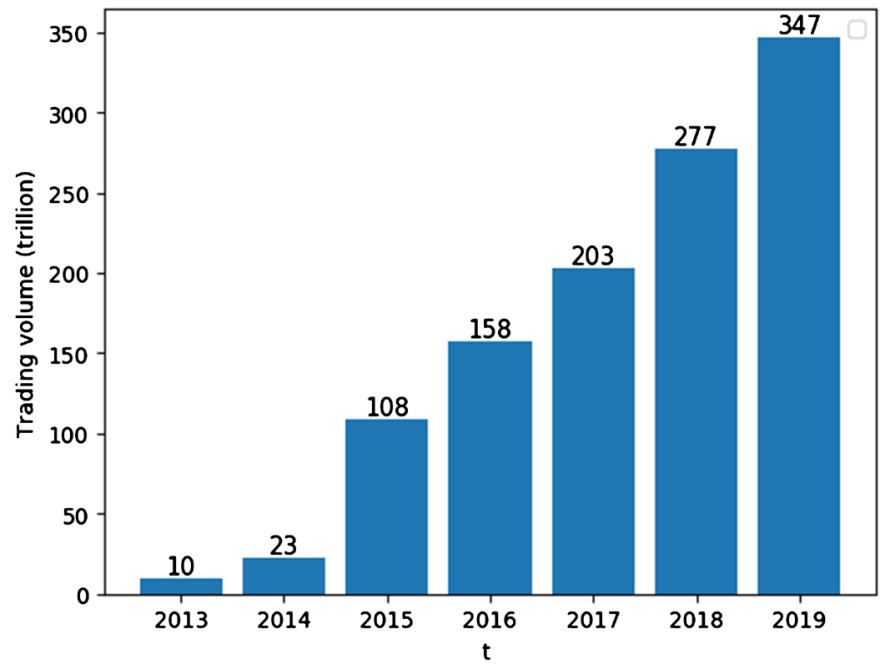

Figure 1. The Growth trend of mobile payment in China. 
many potential mobile payment technology adopters are yet to be developed?" As a service innovation technology, mobile payment is subject to innovation diffusion theory. Meanwhile, the development of innovative diffusion modeling methods has now entered a new stage. As described by Huang (Li, Huang, \& Li, 2017), the special characteristics of service product diffusion include: 1) consumers' decision to adopt service products more rely on internal social impact mechanisms, such as Interpersonal reputation (Dilber \& NcRku, 2014); 2) the diffusion rate is much faster by facing consumers directly, without intermediate processes (Yu, Xiao, \& Gong, 2010); 3) the quality judgment depends more on personal perception, and difficult to have an objective judgement (Ranaweera \& Sigala, 2015). Does the proliferation of payment products also have these characteristics?

With the above questions, the paper starts from the development of China's payment market, firstly introduces several payment methods that have been dominant in China's history. Then, based on the Bass model that considers repeated purchases by customers, the two mainstream products in the current payment market, bank card and mobile payment, are compared and analyzed. The research results show that the internal factors of Interpersonal reputation effect of payment products are significantly stronger than that of mass media; the market capacity of mobile payment products is still large, and payment institutions need to invest more resources in product promotion.

\section{Development Process of China's Payment Market}

\subsection{Grain Card Payment}

In the early days of the founding of the People's Republic of China, due to the low level of economic development, and weak industrial and agricultural foundation, the production of food and commodities is far from meeting needs of national. To guarantee the needs of national life, China introduced an economic model from Soviet Union, that is card payment. With planned distribution of commodity, the country is on the way of planned economy. In 1955, China issued its first grain cards. Within the 39 years of the economic era of card economy, China has issued more than 14,000 types of national grain cards, local grain cards and military grain cards. The card system has very strict rules and regulations. The number of cards issued based on population and one type of card can only use to purchase its corresponding products. The card economy reflected the state's strict control over the distribution of materials and it weakened the ability of capital distribution, which is the objective need of state situation at the time. With the reform of the market economy system and the improvement of social productivity, the shortage of commodities and the shortage of food and other living resources have gradually been resolved. China terminated the circulation of grain card on July 1, 1993, marking that the card payment has finally completed its mission and exited the stage of history. 


\subsection{Cash Payment}

With the change of the economic system, the increase of productivity and the active commodity market, cash has become the main payment tool for the people. People's daily traffic, shopping and travel cannot happen without cash. Price mechanisms and supply balance mechanisms work through cash payments. Cash payment allows people to choose different prices and quality products according to their economic level, which brings convenience to people's lives. At present, cash payments are still an indispensable means of payment.

\subsection{Bank Card Payment}

In 1985, the Bank of China Zhuhai Branch issued China's first RMB credit card, the Pearl River Credit Card, which marked the beginning of the development of China's bank cards. Subsequently, major commercial banks in China successively issued their own credit cards and gradually moved from developed coastal areas to nationwide. By the end of 2019, 8.419 billion bank cards were issued in China, and the average person holds 6.03 bank cards. The bank card has both savings and payment functions, which makes up for the insecurity and inconvenience of large cash transactions. It not only reduces the circulation of cash and checks, but also breaks the time and space restrictions of banking operations, which also leads to electronic payments. Bank card payment was a traditional payment method before the advent of Internet payment and mobile payment. At present, it still occupies a considerable share in China's offline payment market.

\subsection{Internet Payments}

The development of Internet technology and the rapid development of the number of Internet users in China have brought about the rise of e-commerce. In 1999, Alibaba was founded, launched a B2C shopping website, and online shopping began to gain public attention. In October 2003, Alipay went online and resolved the trust crisis in China's Internet shopping through third-party funds hosting. And soon, Alipay became the largest third-party payment platform. In the Internet payment system, there are multiple choices, such as online banking service issued by commercial banks, Alipay wallets by third-party institutions, and WeChat payment, etc. During the interaction between third-party payment institution and commercial bank, payment messages need to be transferred through the two organizations, namely, NetsUnion and UnionPay. As a payment service provider (payment platform operator), third-party payment institutions are independent of financial institutions and mobile operators.

\subsection{Mobile Payment}

Consumers' Internet access model has shifted from the PC to the mobile phone, and the battlefields of various payment market participants have also shifted to the mobile phone. From 2011 to 2012, China Unicom, China Mobile, and China Telecom successively established e-commerce companies and launched mobile 
payment products. At the same time, Alipay launched barcode payment, which opened the prelude to mobile payment. In 2013, the WeChat launched its payment function, and broke Ali's monopoly in mobile payment area. Different from traditional payment, mobile payment has completely broken the time and space restrictions of payment. Consumers can complete payment at any time through mobile terminals. Participants in various payment markets are constantly making technological innovations, while each commercial bank has seized the mobile payment market by promoting mobile banking products and mobile payment acquiring systems that are compatible with mobile payment functions to consumer and merchant users.

According to the payment use scenario and interaction process, mobile payment can be divided into remote payment and near field payment. Remote payment refers to a payment method that does not rely on physical media (two-dimensional code, NFC chip), but uses SMS or Internet to build connection and information exchange with backend payment system, to achieve payment functions such as fund transfer or consumption; near-field payment refers to payment through Mobile phones and other entities accept terminals, based on short-range wireless communication technology or code scanning payment technology, access the acquiring network online or offline to transfer money and funds. The remote payment architecture is similar to the Internet payment. The difference is that mobile remote payment is initiated on a mobile terminal, while Internet payment is generally initiated on a personal computer. The near-field payment scenario is that consumers interact with merchant acquiring systems through mobile terminals and access commercial banks or third-party payment institutions to complete payments.

\section{Analysis of the Development Trend of Mobile Payment}

\subsection{Model}

Bass (Bass, 1969) believes that consumers' adoption of new products is driven by two major factors: 1) external influences, also called innovation factors, are mainly achieved through mass media (such as newspapers, advertising, marketing activities, etc.) Consumers driven by this factor are called innovators; 2) Internal influences, also called imitation factors, are mainly achieved through Interpersonal reputation effects, that is, word of mouth from purchased consumers to potential consumers, such as security, applicability, service level, etc. Those who are affected by this factor are called imitators. The specific model is as Equation (1):

$$
\frac{f(t)}{1-F(t)}=p+q F(t), F(0)=0
$$

$f(t)$ is the market penetration rate at the time $t, F(t)$ is the cumulative total market penetration rate of $(0, t) ; p$ is the innovation factor; $q$ is the imitation factor. 
Solution for $F(t)=\int_{0}^{t} f(t) d t$ :

$$
F(t)=\frac{1-\mathrm{e}^{-(p+q) t}}{1+\frac{q}{p} \mathrm{e}^{-(p+q) t}}
$$

Derivative of $F(t)$ to get Equations (3) and (4):

$$
\begin{gathered}
f(t)=\frac{(p+q)^{2}}{p} \frac{e^{-(p+q) t}}{\left[1+\frac{q}{p} e^{-(p+q) t}\right]^{2}} \\
N(t)=M \frac{1-\mathrm{e}^{-(p+q) t}}{1+\frac{q}{p} \mathrm{e}^{-(p+q) t}} \\
n(t)=M \frac{(p+q)^{2}}{p} \frac{\mathrm{e}^{-(p+q) t}}{\left[1+\frac{q}{p} \mathrm{e}^{-(p+q) t}\right]^{2}}
\end{gathered}
$$

$n(t)$ is the cumulative number of purchases for the market at time $t ; N(t)$ is the cumulative number of purchases for the market; $M$ is the maximum market potential. The Bass model does not consider the repeated purchase behavior of consumers. However, as a service product, the repeated purchase behavior of consumers is very common. In order to make the diffusion model more consistent with market changes, this paper referred to Wang's research (Wang \& Shang, 2002) and added the repeat purchase rate $\omega$ to the Bass model. Considering the behavior of consumers adopting multiple payment methods at the same time, set the repeat purchase time $T_{0}$ to 0 , that is, as soon as mobile payment products are launched on the payment market, there will be repeated consumer adoption behaviors in the market. And get the cumulative number of buyers $\bar{n}(t)$ with Equation (6) in the market at the moment $t$.

$$
\bar{n}(t)=M\left\{\frac{(p+q)^{2}}{p} \frac{\mathrm{e}^{-(p+q) t}}{\left[1+\frac{q}{p} \mathrm{e}^{-(p+q) t}\right]^{2}}+\omega\left[\frac{1-\mathrm{e}^{-(p+q) t}}{1+\frac{q}{p} \mathrm{e}^{-(p+q) t}}\right]\right\}
$$

To make $\bar{n}(t)$ maximum, the time $T^{*}$ is:

$$
T^{*}=\frac{1}{p+q} \ln \frac{q(p+q+\omega)}{p(p+q-\omega)}
$$

Maximum value of $\bar{n}(t)$ is:

$$
\bar{n}(t)=M\left[\frac{(p+q+\omega)(p+q-\omega)}{4 q}+\frac{(q+\omega-p)}{2 q}\right]
$$

\subsection{Empirical Analysis}

This study selects the consumer-oriented mobile payment product mobile banking 
released by commercial banks as the empirical research object. According to the data from the "China Mobile Banking Market Quarterly Monitoring Report Q4 2018" released by Analysys Industry Database, in the fourth quarter of 2018, China’s mobile banking customer transaction scale was $¥ 77.1$ trillion, of which Industrial and Commercial Bank of China, China Construction Bank, Agricultural Bank of China, Bank of China, Bank of Communications, China Merchants Bank, China CITIC Bank, Shanghai Pudong Development Bank and China Minsheng Bank accounted for more than $80 \%$ of the total market share of consumers and market transactions. This article's research focused on the nine banks, divided the nine banks into two categories according to the bank type and size. The first four state-owned large banks are in one category. These banks have strong capital and provide solid conditions for the proliferation of mobile banking products. The other five banks are in another category. These banks are smaller in capital and scale than the first category, but they are more innovative in mobile banding products. The mobile banking products of these two types of banks are named $\mathrm{B}_{1}$ and $\mathrm{B}_{2}$ respectively.

In order to ensure the validity of the model, this resource introduced two types of traditional payment products, bank card and credit card, as a comparison. Table 1 shows the data sources and sample ranges of various payment products.

In this paper, nonlinear least squares (NLS) method is used to estimate the parameters of the model. The advantage of this method is that it can effectively deal with multi-parameter models and reduce the errors caused by the selection of time points. The parameters to be estimated in the model are $(M, p, q, \omega)$. The initial setting of the parameters in the model is based on the research of previous scholars (Libai, Muller, \& Peres, 2009; Van den Bulte \& Joshi, 2007). The obtained parameter estimation results are shown in Table 2.

The following conclusions can be drawn from Table 2:

Table 1. Data sources and sample ranges of various payment products.

\begin{tabular}{ccccc}
\hline Payment products & data sources & sample ranges & unit & scale \\
\hline credit card & China Statistical Yearbook & $2009-2018$ & Billion & Annual data \\
debit card & China Statistical Yearbook & $2009-2018$ & Billion & Annual data \\
$\mathrm{B}_{1}$ Mobile Banking & Annual reports of commercial banks & $2009-2018$ & Billion & Annual data \\
$\mathrm{B}_{2}$ Mobile Banking & Annual reports of commercial banks & $2009-2018$ & Billion & Annual data \\
\hline
\end{tabular}

Table 2. Parameter estimation results for different service products.

\begin{tabular}{ccccccc}
\hline Payment products & Adoption (2018) & $\boldsymbol{m} \times 10^{4}$ & $\boldsymbol{p}$ & $\boldsymbol{q}$ & $\boldsymbol{\omega}$ & $\boldsymbol{F} \times 10^{3}$ \\
\hline credit card & 6.86 & 10.70 & 0.068767 & 0.854538 & 0.8758 & 5.6 \\
debit card & 69.11 & 84.61 & 0.017672 & 0.465356 & 4.0175 & 45.4 \\
B 1 Mobile Banking & 10.34 & 16.54 & 0.049075 & 0.434358 & 1.7758 & 3.7 \\
B 2 Mobile Banking & 2.46 & 9.58 & 0.000046 & 0.647769 & 2.4033 & 0.4 \\
\hline
\end{tabular}


- In each payment product model, $p$ is much smaller than internal effect $q$, which indicates that the internal factors of interpersonal reputation effect are significantly stronger than the external effects of mass media (advertising, promotion, etc.). In China's payment market, consumers still have relatively conservative concept while adopting service products, and their ability to bear product trial risks is not great. The fitting results of this paper found that the average value of $p$ is 0.03 and the average value of $p_{2}$ is 0.045 , which are similar to the conclusions of Mahajan (Mahajan, Muller, \& Bass, 1995); and the average value of $q$ is 0.60 , which is much larger than 0.4 . The above results showed that when consumers adopt payment products, they pay attention to internal social influence mechanisms, especially influences, which not only produce interpersonal reputation effects within their groups, but also cross-population. Therefore, payment institutions should pay more attention on this consumer group when formulating marketing strategies.

- Comparing the parameters of two types of mobile banking payment product diffusion model, it can be found that the $p$ value of joint-stock banks is significantly smaller than that of large state-owned banks, while the $q$ value is the opposite. This phenomenon may be because large state-owned banks invest more in mass media (advertising, promotion, etc.) so that the effect is more significant; joint-stock banks have established a good reputation among customer groups due to personalized services.

- From the perspective of potential market capacity, there is not much room for the proliferation of traditional payment products like debit card and credit card, especially debit card products are close to the upper limit of the potential market capacity. Two types of mobile banking payment products have ample room for potential adopters.

- Each service product's $R^{2}$ reached more than $96 \%$, indicating that the model fit is very effective, and the F-test results of the model are very significant.

The fitting effect of B1 and B2 mobile banking users is shown in Figure 2 and Figure 3. It can be seen from the figure that the fitted data is very close to the actual data and the effect is very good.

\subsection{Comparative Analysis of Model Fitting}

In order to fit the model, this paper compares the reconstructed model with the Bass model to check the fitting accuracy of the model. The fitting error uses two indicators: MAPE (Mean Absolute Percent Error) and RMSE (Root Mean Squared Error). The calculation process of MAPE and RMSE are shown in Equation (9) and Equation (10).

$$
\begin{gathered}
M A P E=\text { mean }\left(\left|\hat{y}_{i}-y_{i}\right| / y_{i}\right) \times 100 \% \\
R M S E=\sqrt{\operatorname{mean}\left[\left(\hat{y}_{i}-y_{i}\right)^{2}\right]}
\end{gathered}
$$

$y_{i}$ is the actual value and $\hat{y}_{i}$ is the predicted value. The smaller the value of 
$M A P E$ and $R M S E$, the better the prediction effect. The MAPE results and RMSE results of models are shown in Table 3.

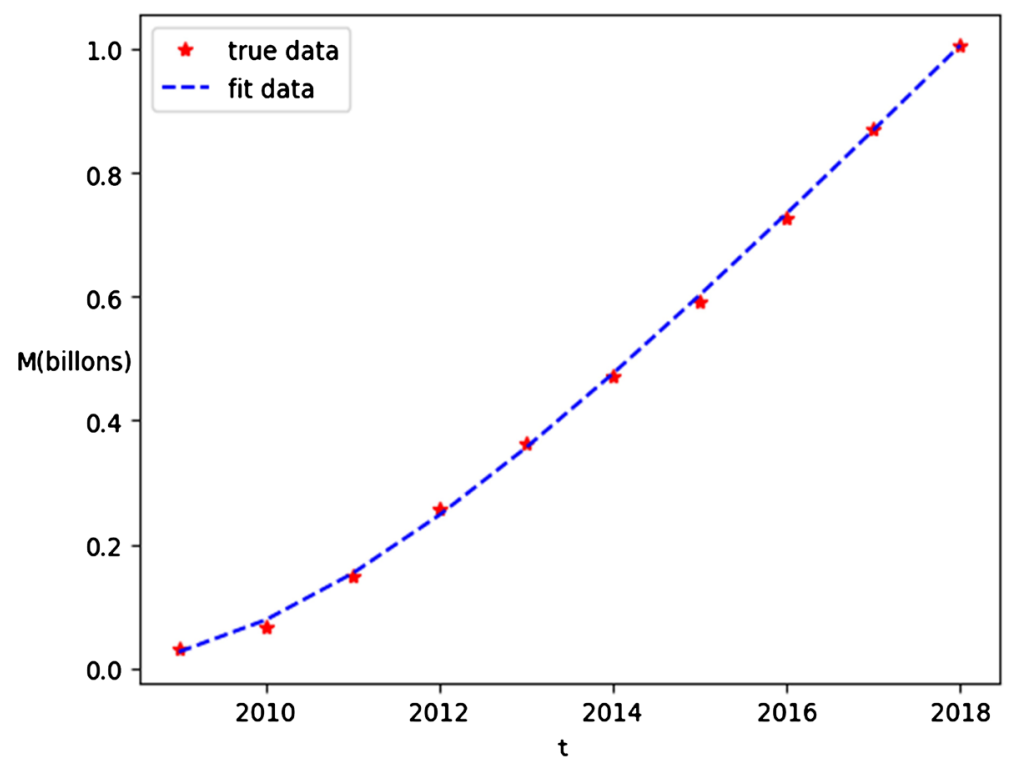

Figure 2. The fitting effect of B1 mobile banking users adopt.

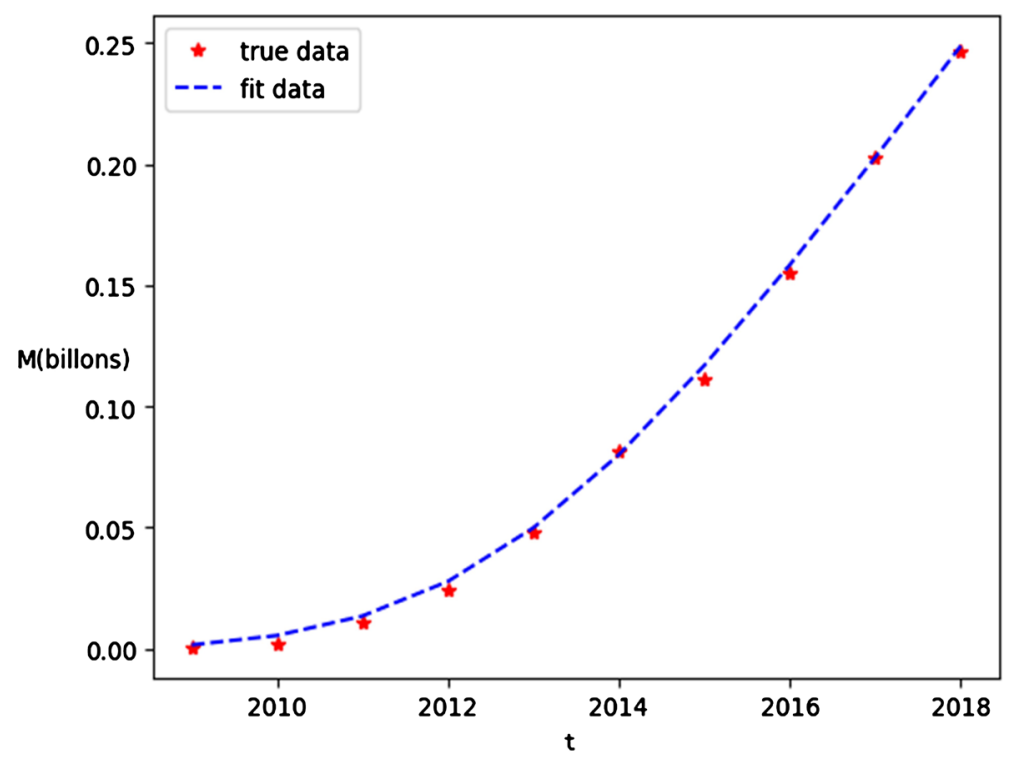

Figure 3. The fitting effect of B2 mobile banking users adopt.

Table 3. The MAPE results and RMSE results of models.

\begin{tabular}{|c|c|c|c|c|c|}
\hline \multirow{2}{*}{ Model } & \multirow{2}{*}{ indicators } & \multicolumn{4}{|c|}{ product } \\
\hline & & debit card & credit card & $\mathrm{B}_{1}$ Mobile Banking & $\mathrm{B}_{2}$ Mobile Banking \\
\hline \multirow{2}{*}{ Model in this paper } & $M A P E$ & $4.66 \%$ & $6.11 \%$ & $3.05 \%$ & $5.19 \%$ \\
\hline & $R M S E$ & 0.86 & 0.342 & 0.095 & 0.058 \\
\hline \multirow{2}{*}{ Bass Model } & $M A P E$ & $8.81 \%$ & $11.19 \%$ & $7.51 \%$ & $8.87 \%$ \\
\hline & $R M S E$ & 1.74 & 0.740 & 0.201 & 0.195 \\
\hline
\end{tabular}


It can be seen from Table 3 that the model in this paper has better fitting effect than the Bass model, both from MAPE and RMSE. It shows that the model in this paper has superiority when analyzing the diffusion of payment products such as mobile banking.

\section{Conclusion}

Based on the development of China's payment system, this paper focused on the proliferation of mobile payment products, and built a payment product diffusion model based on the Bass model that considers repeated purchases. The research collected proliferation data of four types of payment products, including bank cards and mobile banking in China, classified mobile banding products into state-owned large-scale banks products and joint-stock banks products based on bank type to conduct multi-dimensional comparative studies. Through empirical analysis, the fitting effect between the model in this paper and the traditional Bass model is tested.

The research results of this article can provide marketing inspiration for payment companies: 1) The payment products' internal factors of the interpersonal reputation effect on diffusion are significantly stronger than those of the mass media. In order to quickly launch new service products, companies can consider cultivate some consumers into influencers. Thus company can not only effectively reduce marketing costs in a concentrated way, but also enlarge the marketing effect and quickly occupy the market; 2) Large-scale state-owned banks and joint-stock banks are significantly affected by external and internal factors, so various types of banks can develop differentiated customer relationship management programs for different consumer groups to increase market share.

In future research, diffusion models can be established from the micro level of consumers or merchants, to explore the impact of heterogeneity of users and mufti-attribute differences of products on diffusion. And acquire enlightenment on marketing and management for different payment companies.

\section{Conflicts of Interest}

The authors declare no conflicts of interest regarding the publication of this paper.

\section{References}

Bass, F. M. (1969). A New Product Growth for Model Consumer Durables. Management Science, 15, 215-226. https://doi.org/10.1287/mnsc.15.5.215

Dilber, M., \& NcRku, L. (2014). The Effects of Word-of-Mouth Message on Purchase Decision in Credence-Based Services. Dumlupinar University Journal of Social Science, 41, 192-212.

Kalinic, Z., Marinkovic, V., Molinillo, S., \& Liébana-Cabanillas, F. (2019). A Multi-Analytical Approach to Peer-to-Peer Mobile Payment Acceptance Prediction. Journal of Retailing and Consumer Services, 49, 143-153. https://doi.org/10.1016/j.jretconser.2019.03.016

Li, Y., Huang, H. L., \& Li, Y. Y. (2017). Diffusion of Service Products with Customer At- 
trition: From the Perspective of Social Influence Heterogeneity. Journal of Systems \& Management, 26, 456-463.

Libai, B., Muller, E., \& Peres, R. (2009). The Diffusion of Services. Journal of Marketing Research, 46, 163-175. https://doi.org/10.1509/jmkr.46.2.163

Mahajan, J., Muller, E., \& Bass, F. M. (1995). Diffusion of New Products: Empirical Generalizations and Managerial Uses. Marketing Science, 14, 79-88.

https://doi.org/10.1287/mksc.14.3.G79

Merhi, M., Hone, K., \& Tarhini, A. (2019). A Cross-Cultural Study of the Intention to Use Mobile Banking between Lebanese and British Consumers: Extending UTAUT2 with Security, Privacy and Trust. Technology in Society, 59, Article ID: 101151.

https://doi.org/10.1016/j.techsoc.2019.101151

PBC (2013). The People's Bank of China Overall Operation of the Payment System in 2013.

PBC (2019). The People's Bank of China Overall Operation of the Payment System in 2019.

Ranaweera, C., \& Sigala, M. (2015). From Service Quality to Service Theory and Practice. Journal of Service Theory and Practice, 25, 2-9. https://doi.org/10.1108/JSTP-11-2014-0248

Sohu (2018). https://www.sohu.com/a/194611232 308613

Van den Bulte, C., \& Joshi, Y. V. (2007). New Product Diffusion with Influentials and Imitators. Marketing Science, 26, 400-421. https://doi.org/10.1287/mksc.1060.0224

Wang, H. Y., \& Shang, Z. T. (2002). The Research on Repurchasing Product Life Cycle Model. Chinese Journal of Management Science, 10, 24-29.

Yu, T. Y., Xiao, R. B., \& Gong, X. G. (2010). Net Game Diffusion Characteristics Based on Multi-Agent. Systems Engineering-Theory \& Practice, 30, 919-927.

Zhou, T. (2012). Examining Mobile Banking User Adoption from the Perspectives of Trust and Flow Experience. Information Technology \& Management, 13, 27-37. https://doi.org/10.1007/s10799-011-0111-8

Zhou, T. (2013). An Empirical Examination of Continuance Intention of Mobile Payment Services. Decision Support Systems, 54, 1085-1091.

https://doi.org/10.1016/j.dss.2012.10.034 